\title{
Effect of high hydrostatic pressure on the barrier properties of polyamide- 6 films
}

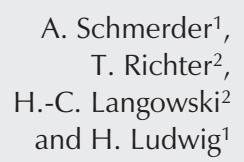

A. Schmerder ${ }^{1}$, T. Richter ${ }^{2}$,

H.-C. Langowski and H. Ludwig 1

\author{
${ }^{1}$ Institut für Pharmazie und Molekulare Biotechnologie, \\ Universität Heidelberg, INF 366, Heidelberg, Germany \\ ${ }^{2}$ Lehrstuhl für Lebensmittelverpackungstechnik, \\ Technische Universität München, Freising, Germany
}

\begin{abstract}
Correspondence
H. Ludwig

Institut für Pharmazie und

Molekulare Biotechnologie

Universität Heidelberg, INF 366

D-69120 Heidelberg

Germany

Fax: +49-6221-545960

E-mail:

horst.ludwig@urz.uni-heidelberg.de

Presented at the 3rd International

Conference on High Pressure

Bioscience and Biotechnology,

Rio de Janeiro, RJ, Brazil,

September 27-30, 2004.

Research supported by the Deutsche Forschungsgemeinschaft (Project Nos. LU 171/10-1, LU 171/10-2, and WE 989/13-1).
\end{abstract}

Received December 17, 2004 Accepted May 17, 2005

\begin{abstract}
Little is known about the barrier properties of polymer films during high pressure processing of prepackaged foods. In order to learn more about this, we examined the influence of high hydrostatic pressure on the permeation of raspberry ketone (dissolved in ethanol/water) through polyamide- 6 films at temperatures between 20 and $60^{\circ} \mathrm{C}$. Permeation was lowered by increasing pressure at all temperatures. At $23^{\circ} \mathrm{C}$, the increasing pressure sequence $0.1,50,100,150$, and $200 \mathrm{MPa}$ correlated with the decreasing permeation coefficients $\mathrm{P} /\left(10^{9} \mathrm{~cm}^{2} \mathrm{~s}^{-1}\right)$ of $6.2,3.8$, 3.0, 2.2, and 1.6. Analysis of the permeation kinetics indicated that this effect was due to a reduced diffusion coefficient. Pressure and temperature acted antagonistically to each other. The decrease in permeation at $200 \mathrm{MPa}$ was compensated for by a temperature increase of $20^{\circ} \mathrm{C}$. After release of pressure, the former permeation coefficients were recovered, which suggests that this 'pressure effect' is reversible. Taken together, our data revealed no detrimental effects of high hydrostatic pressure on the barrier properties of polymer films.
\end{abstract}

\section{Introduction}

During high pressure processing of prepackaged foods, the volumes decrease considerably, e.g., $15 \%$ at $600 \mathrm{MPa}$ in case of aqueous foods. Therefore, the packaging materials of choice are polymer films. Unfortunately, only limited information is available about the barrier properties of polymers under pressure (1-3). In order to learn more about this, we examined the permeation of food components through polymer films under the influence of high hydrostatic pressure. We present here the results obtained with the aroma compound raspberry ketone in aqueous solution packed in polyamide-6 films.

\section{Material and Methods}

Raspberry ketone (4-(4-hydroxyphenylbutan-2-on)), 99\% purity, was used (Aldrich, Steinheim, Germany). The polyamide- 6 film was a gift from BASF AG, Ludwigshafen, Germany. Its thickness was $55 \mu \mathrm{m}$ as determined by measurements with a micrometer screw.

High pressure experiments were performed by two different methods:

1. The permeated amount of raspberry ketone after pressure release was measured by the modified 'bag in the bag' method (2). For that, sheets of polyamide- $6(4 \times 6 \mathrm{~cm})$ were folded to a size of $2 \times 6 \mathrm{~cm}$ and sealed 

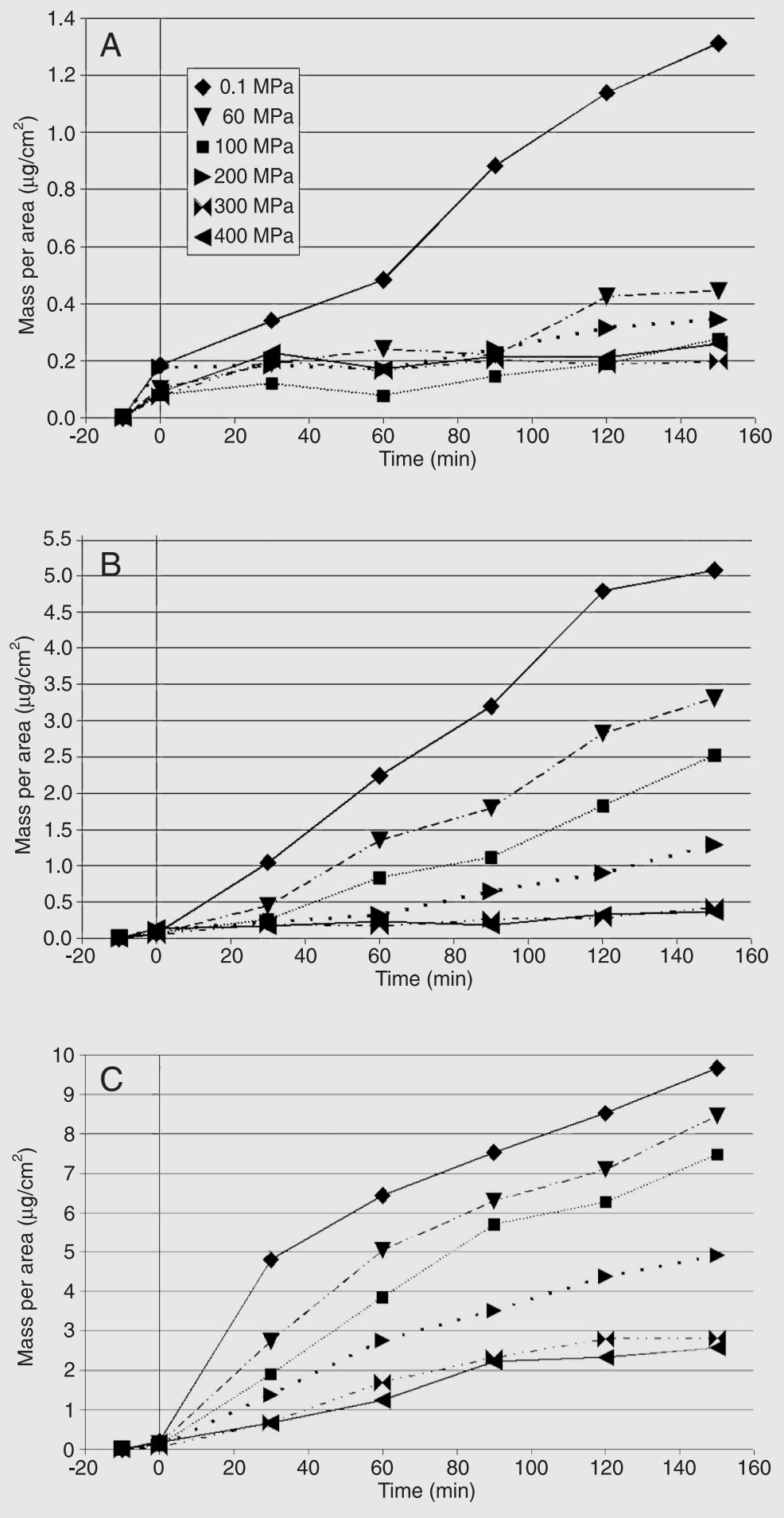

Figure 1. Permeation of raspberry ketone through polyamide- 6 films at $22^{\circ} \mathrm{C}(\mathrm{A}), 40^{\circ} \mathrm{C}(\mathrm{B})$ and $60^{\circ} \mathrm{C}(\mathrm{C})$ and under different pressures. The bags started to be filled at $-10 \mathrm{~min}$ and the desired pressures were reached at $0 \mathrm{~min}$. Note that the ordinates are the same but the scales are different. on three sides, resulting in an open bag with a surface of about $20 \mathrm{~cm}^{2}$. A solution of 400 $\mu \mathrm{g}$ raspberry ketone in $1 \mathrm{ml}$ water/ethanol (90/10\% volume) was added to the bag. The bag was sealed and placed into an $8.5-\mathrm{cm}$ long teflon tube with an outer diameter of 1 $\mathrm{cm}$ (wall thickness $1 \mathrm{~mm}$ ), that contained 2.4 $\mathrm{ml}$ of deionized water. Avoiding inclusion of air, the teflon tube was closed by a movable piston to allow for pressure-induced volume changes. Seven tubes were prepared in parallel for each pressure/temperature combination. The tubes were placed into microautoclaves $1.6 \mathrm{~cm}$ in diameter, pressurized and thermostated $(4,5)$. Ten minutes after starting the preparation of experimental set-up, both pressure and temperature were stable (time zero of the experiment). At that time the first and the last of the seven prepared tubes were opened and analyzed to determine the permeation during the 'comeup time' (filling the pouches, handling time and reaching the desired pressure and temperature). The mean value of the two samples was used as the starting point at time zero. The remaining five samples were stopped at 30, 60, 90, 120, and 150 min after the "time zero' time point. After pressure release and bag opening, the concentrations of raspberry ketone inside and outside the polyamide- 6 bags were measured by UV-spectroscopy at $276 \mathrm{~nm}$. The amount of substance absorbed in the polymeric films was determined by mass balance calculations, and was also controlled by direct measurements.

2 . The permeation under pressure was measured in situ (6). A polyamide-6 film with a surface area of $1.54 \mathrm{~cm}^{2}$ was clamped between the upper chamber (14.61-ml volume filled with a solution of $400 \mu \mathrm{g}$ raspberry ketone per ml deionized water) and the lower chamber $(5.39 \mathrm{ml}$ deionized water, equipped with a magnetic stirrer). The 'dead time' required to start the experimental procedures (stable pressure) was about 3 min and was negligible compared to the much longer observation times. The lower cham- 
ber was equipped with two optical windows to detect the permeated raspberry ketone via UV spectroscopy.

\section{Results}

Figure 1A shows the permeation of raspberry ketone through polyamide- 6 films at room temperature and under different pressures measured by the 'bag in the bag' method. Permeation was strongly inhibited by pressures above $60 \mathrm{MPa}$ and this effect was counteracted by increasing temperatures. At $40^{\circ} \mathrm{C}$ (Figure 1B), the permeation rate of raspberry ketone at atmospheric pressure was five times greater than that at room temperature. The rate was gradually reduced with increasing pressure so that a combination of $40^{\circ} \mathrm{C}$ and 200 $\mathrm{MPa}$ resulted in the same permeation rate as a combination of $22^{\circ} \mathrm{C}$ and $0.1 \mathrm{MPa}$. The permeation rate approached zero at pressures of 300 and $400 \mathrm{MPa}$ and at $40^{\circ} \mathrm{C}$. At $60^{\circ} \mathrm{C}$, the permeation increased further (Figure 1C), and again the effect of a pressure rise of $200 \mathrm{MPa}$ was counteracted by a temperature increase of $20^{\circ} \mathrm{C}$. The permeation was similar for $60^{\circ} \mathrm{C} /$ $200 \mathrm{MPa}$ and $40^{\circ} \mathrm{C} / 0.1 \mathrm{MPa}$. The bent curves in Figure 1C indicate that permeation slowed down due to saturation effects. This was even more apparent from the data showing the redistribution of raspberry ketone between the solution inside the bag and the solution outside and inside the plastic film itself at atmospheric pressure as a function of time (Figure 2A). The diffusion approached equilibrium. A substantial fraction of the raspberry ketone ( 75 of $400 \mu \mathrm{g}$ ) was absorbed by the plastic film after it had already reached a quasi-stationary state after $30 \mathrm{~min}$ (the concentration inside the film remained constant). At a pressure of 400 MPa (Figure 2B), the film absorbed the same amount of substance as at atmospheric pressure, but the diffusion was very slow under these conditions.

Figure 3 shows the principles of the in situ experiments. The conditions were chosen (see Material and Methods) in such a
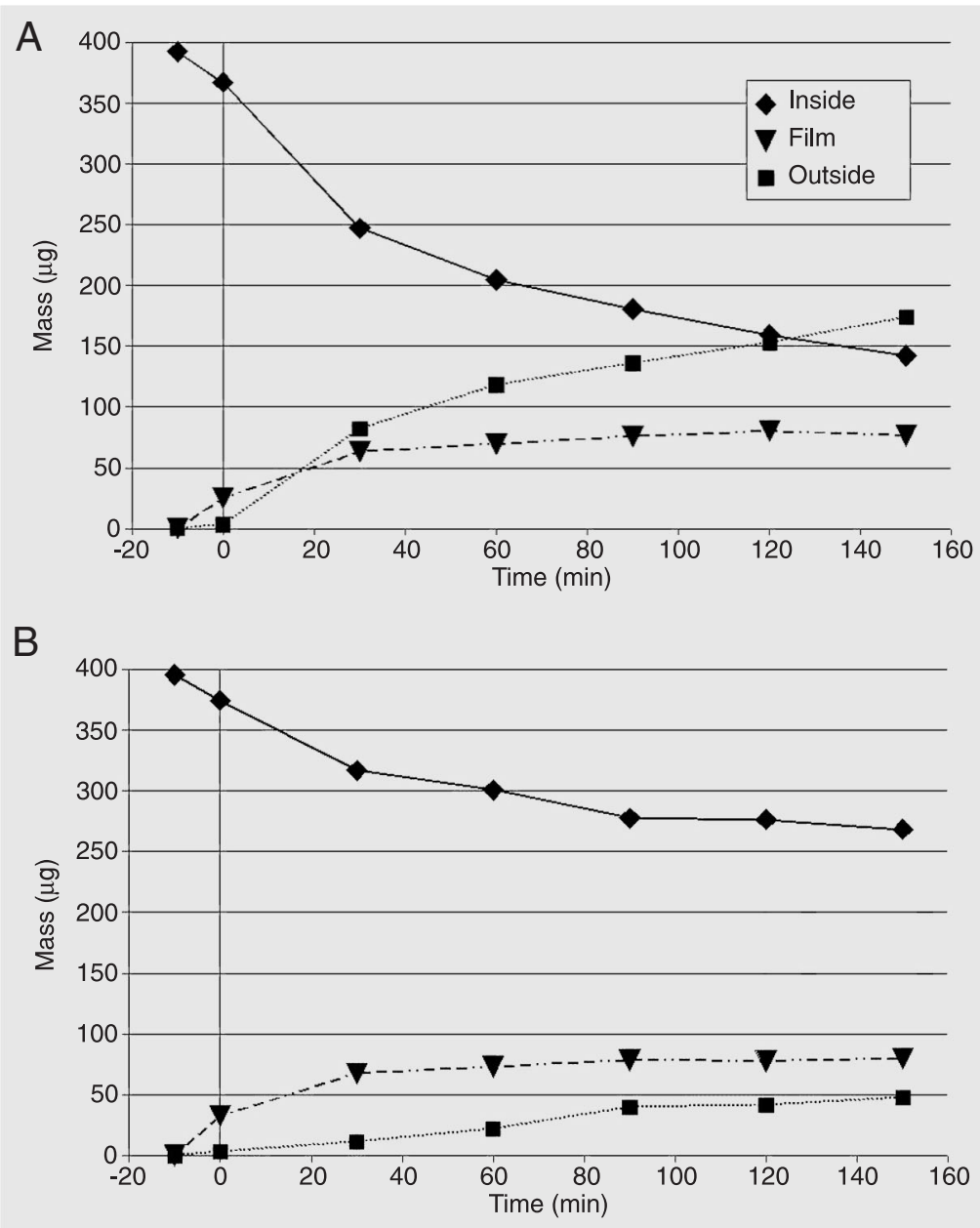

Figure 2. Redistribution of raspberry ketone by permeation through polyamide- 6 films at $60^{\circ} \mathrm{C}$ at $0.1 \mathrm{MPa}(\mathrm{A})$ and at $400 \mathrm{MPa}(\mathrm{B})$.

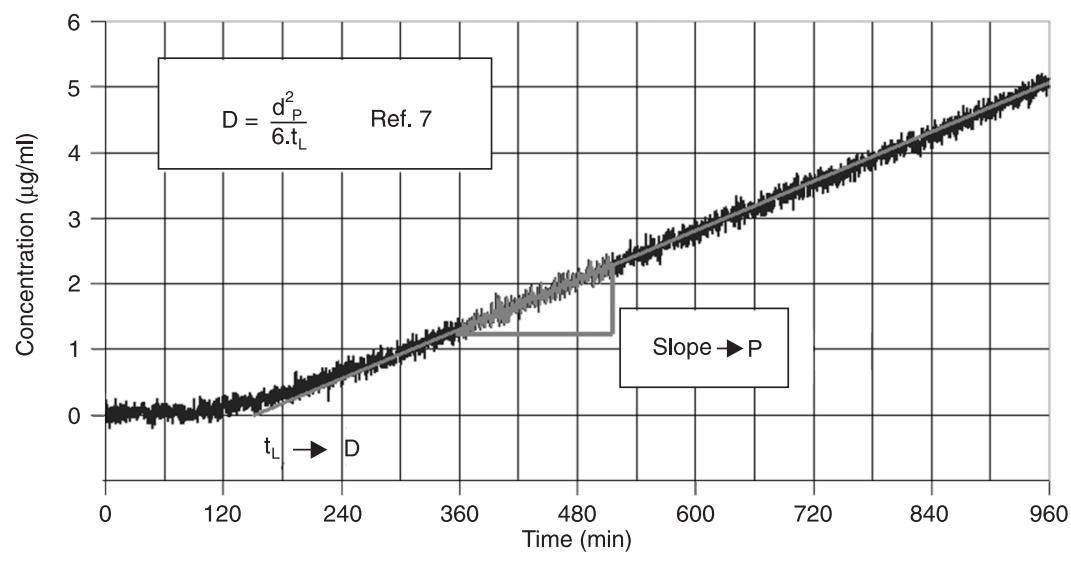

Figure 3. In situ measurement of the permeation of raspberry ketone through polyamide- 6 films at $23^{\circ} \mathrm{C}$ and $50 \mathrm{MPa}$. $t_{L}=$ lag time; $d_{p}=$ thickness of polymer film; $D=$ diffusion coefficient; $P=$ permeation coefficient. 
way that a stationary state was reached after a 'lag' time. The permeation coefficient $P$ was obtained from the slope of the stationary straight line, and the diffusion coefficient D was obtained from the 'lag' time (7). Using the equation $\mathrm{P}=\mathrm{D}^{*} \mathrm{~K}$, the partition ratio $\mathrm{K}=$ $\mathrm{C}$ (polymer)/C (solution) can be calculated, giving the ratio of the concentration of the permeating substance on the polymer surface to that of the adjacent solution. Figure 4 shows the permeation of raspberry ketone through polyamide- 6 over a period of $16 \mathrm{~h}$ at room temperature and at pressures of up to

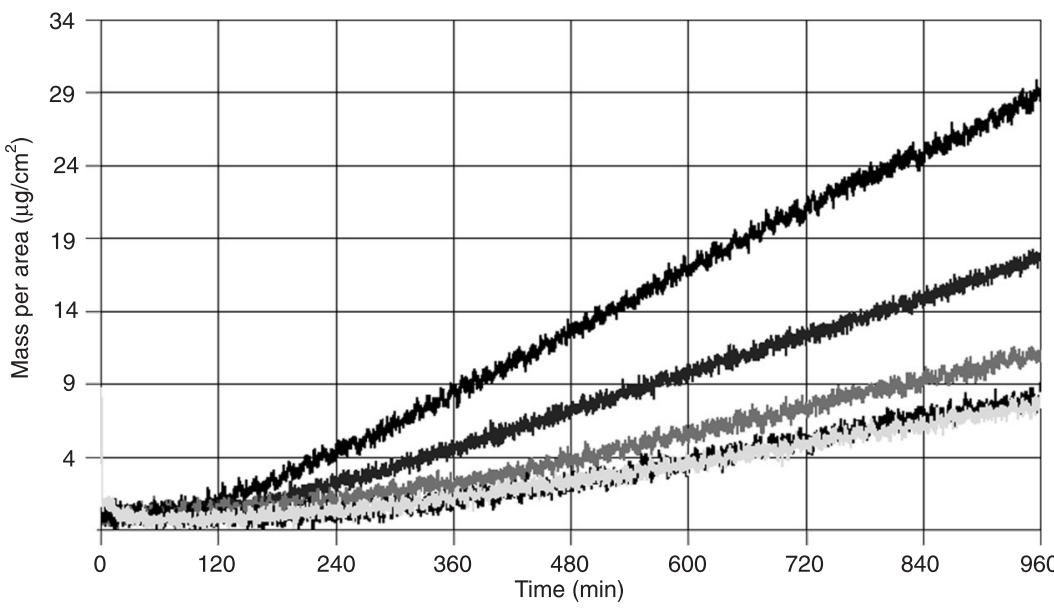

Figure 4. In situ measurements of the permeation of raspberry ketone through polyamide- 6 films at $23^{\circ} \mathrm{C}$ and under different pressures of $0.1,50,100,150$, and $200 \mathrm{MPa}$ (from top to bottom in the figure). The data for 150 and $200 \mathrm{MPa}$ are superimposed.

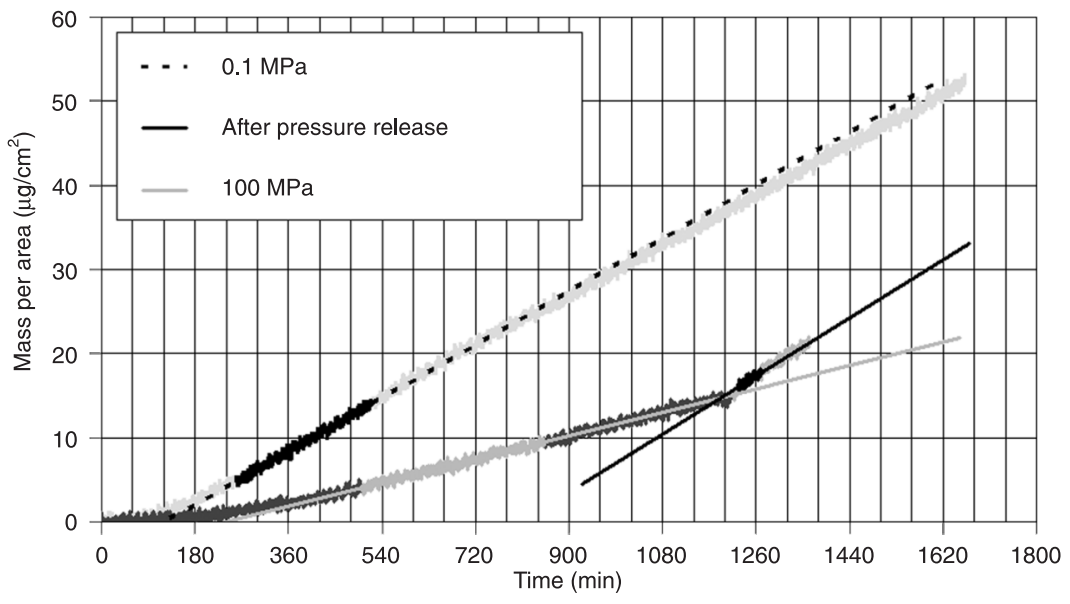

Figure 5. Reversibility of the permeation of raspberry ketone through polyamide- 6 films at $23^{\circ} \mathrm{C}$.
$200 \mathrm{MPa}$. The results of the in situ method were qualitatively the same as the results obtained using the 'bag in the bag' method, but the in situ method had the advantage that the permeation parameters $\mathrm{P}, \mathrm{D}$ and $\mathrm{K}$ could be derived more precisely. In Figure 5, the permeation rates (slopes of the curves) at 0.1 and $100 \mathrm{MPa}$ are compared. The permeation rate was reduced by half by pressure treatment with $100 \mathrm{MPa}$. When the pressure was released after $20 \mathrm{~h}$, the permeation rate returned back to that at atmospheric pressure almost immediately.

\section{Discussion}

An analysis of the curves in Figure 4 reveals that the slopes of the straight lines and the corresponding 'lag' times behave in an inversely proportional manner when the pressure rises. This indicates the same pressure dependence of the permeability and the diffusion coefficients, whereas the partition coefficient remains nearly constant. It therefore appears that the reduced permeation under pressure is caused by hindered diffusion through the polymer matrix.

The polymer has crystalline and amorphous regions. Only the amorphous regions can be penetrated by the diffusing substance. Measurement of the amorphous part of polyamide- 6 by differential scanning calorimetry suggested that it represents $47 \%$ of the film. This fraction was not changed by pressure. Thus, the pressure effects are likely to be due to the action of pressure on the already existing amorphous parts of the polymer. In amorphous polymers, the molecular chains are mobile, thus forming transient 'free volumes' that are used by diffusing particles to travel inside the polymer. A rise in temperature increases the free volume, whereas a rise in pressure decreases it $(3,8,9)$. Another feature of amorphous polymers is that they undergo the 'glass transition', which is characterized by the 'glass transition' temperature. Below this temperature, movements of 
the molecular chains are drastically restricted, and the free volume is small and does not change very much with pressure. Therefore, at temperatures below the 'glass transition' temperature, there is only very slow permeation, which is nearly unaffected by pressure. On the other hand, the glass transition temperature itself is shifted under pressure. Depending on the polymer, it increases by 10 to $30^{\circ} \mathrm{C}$ per $100 \mathrm{MPa}$ (10). For polyamide- 6 , the glass temperature is about $40^{\circ} \mathrm{C}$ at atmospheric pressure (Applikationssammlung Thermische Analyse, Mettler Toledo, Giessen, Germany). It is therefore reasonable to assume that polyamide- 6 was in the state below the glass temperature in all our experiments at 300 and $400 \mathrm{MPa}$.

At room temperature and atmospheric pressure (Figure 1A) only a small amount of raspberry ketone penetrated the plastic film, and there was even less penetration under higher pressures. One reasonable explanation for this could be that the glass tempera- ture is higher than room temperature, and it is even higher under the applied pressures. At $40^{\circ} \mathrm{C}$ (Figure $1 \mathrm{~B}$ ), the permeation was much greater, with a gradual reduction at increasing pressure up to $300 \mathrm{MPa}$. There was no significant difference in the permeation at 300 and $400 \mathrm{MPa}$, and almost nothing permeated. The reason for this could be either that the glass transition temperature is substantially higher than $40^{\circ} \mathrm{C}$ at these pressures, or that the free volume has already reached a minimum at $300 \mathrm{MPa}$ and thus cannot be reduced further by the increasing pressure. At $60^{\circ} \mathrm{C}$, the results were similar to those at $40^{\circ} \mathrm{C}$, apart from the fact that the permeation was faster.

The reversibility of the pressure effects supports the explanations given above. These data have shown that the barrier properties of polyamide- 6 films are improved under hydrostatic pressure and the films are not damaged when the pressure is released.

\section{References}

1. Ludwig H, Marx H \& Tauscher B (1994). Interaction of food packaging material and selected food components under high pressure. High Pressure Research, 12: 251-254.

2. Kübel J, Ludwig H, Marx $\mathrm{H}$ et al. (1996). Diffusion of aroma compounds into packaging films under high pressure. Packaging Technology and Science, 9: 143-152.

3. Schauwecker A, Balasubramaniam VM, Sadler G et al. (2002). Influence of high pressure processing on selected polymeric materials and on the migration of a pressure-transmitting fluid. Packaging Technology and Science, 15: 255-262.

4. Butz P, Ries J, Traugott $U$ et al. (1990). Hochdruckinaktivierung von Bakterien und Bakteriensporen. Pharmazeutische Industrie, 52: 487491.

5. Sojka B \& Ludwig H (1994). Pressure induced germination and inactivation of Bacillus subtilis spores. Pharmazeutische Industrie, 56: 660-663.

6. Götz J \& Weisser H (2002). Permeation of aroma compounds through plastic films under high pressure: in situ measuring method. Innovative Food Emerging Science and Technologies, 3: 25-31.

7. Barrer RM (1941). Diffusion in and through Solids. University Press, Cambridge, UK.

8. Vieht WR (1991). Diffusion in and through Polymers - Principles and Applications. Carl Hanser Verlag, Munich, Germany.

9. Kovarskii AL (1994). High Pressure Chemistry and Physics of Polymers. CRC Press Inc., Boca Raton, FL, USA.

10. Bianchi U (1965). Pressure effects on glass transition in polymers. Journal of Physical Chemistry, 69: 1497-1504. 